\title{
Full-Scale Drop Test of a Fokker F28 Wingbox Fuselage Section
}

\author{
J. D. Littell ${ }^{1}$
}

\begin{abstract}
${ }^{1}$ NASA Langley Research Center, Research Directorate, Structural Dynamics Branch, Mail Stop 495, 14 West Bush Road, Hampton, VA 23681; PH (757) 8645195; FAX (757) 864-8547; email: Justin.D.Littell@nasa.gov
\end{abstract}

\section{ABSTRACT}

During the summer of 2017, a vertical drop test was conducted on a partial section of a Fokker F28 MK4000 aircraft as a part of a joint NASA/FAA effort to investigate the performance of transport category aircraft under realistic crash conditions. Ten Anthropomorphic Test Devices (ATDs, a.k.a. crash test dummies) ranging from $5^{\text {th }}$ to $95^{\text {th }}$ percentile sizes were used for the collection and comparison of occupant loads. Additionally, overhead bin mass simulators were added to achieve a realistic fuselage configuration. The section was dropped with a downward facing pitch angle onto a sloping soil surface in order to simulate a local horizontal velocity in the airframe.

Instrumentation consisting of accelerometers was installed to measure floor, seat track, ATD, and overhead bin acceleration responses. Self-contained data recorders logging accelerations and rotational rates were also used on the seat tracks and lower structure as evaluations for crash recording devices in potential future use cases. The right side of the section was painted with a stochastic black and white speckle pattern for use in full field photogrammetric imaging techniques. Results collected from the airframe accelerometers will be presented, and deformation and failures of the test article structure will be discussed. Finally, an examination of the test article motion will be presented using derived components of local velocities with their effect on the impact acceleration and airframe response.

\section{INTRODUCTION}

Vertical drop tests of partial fuselage sections (commonly called "barrel drops" or "barrel sections") have occurred for transport category aircraft at different times in the past. A set of drop tests were conducted in the 1980s by NASA Langley Research Center (LaRC) for the preliminary acquisition of occupant, structural and seat loadings from Boeing 707 fuselage sections (Williams 1983) in preparation for a full-scale crash test, known as the Controlled Impact Demonstration (CID) which occurred in 1984 (Fasanella 1986). More recently, a series of barrel section drop tests of both Boeing 737 (Abramowitz 2000) and Boeing 707 (Logue 1995) fuselage sections were conducted by the Federal Aviation Administration (FAA). One of these was used to evaluate airframe interaction with auxiliary fuel tanks present, but also collected airframe, seat and occupant loads for evaluation of injury metrics. The FAA used this information as a precursor for vertical drop tests of full aircraft, including an ATR42300 (Abramowitz 2006), Metro III (McGuire 1993), Beechcraft 1900C (McGuire 
1998) and a Shorts 3-30 (Abramowitz 1999). All of these drop tests were conducted for the investigation of structural response of the aircraft and occupant injury for (simulated) crashes under severe but survivable conditions.

In 2017, through a collaborative agreement with FAA and NASA LaRC, a research effort was undertaken to obtain impact data through a series of tests which will support the development of airframe level crash requirements for transport category airplanes (Federal Register 2015). Two Fokker F28 MK4000 fuselage sections, which currently reside at NASA LaRC's Landing and Impact Research facility (LandIR) (Vaughn 1976) were drop tested. The F28 MK4000 is a high performance twin-turbo fan narrow-body aircraft with seating in a triple-double configuration, capable of carrying up to 85 passengers on medium range length routes. The majority of the F28 fleet has retired from service, with only a handful of still airworthy aircraft operated by African commercial carriers. This paper will discuss the test setup and results from a drop test of a Wingbox Section conducted on June 29, 2017.

\section{TEST SETUP}

The F28 Wingbox Section was cut between fuselage frame sections (FS) 9805 and 12405 from a F28 MK4000 full fuselage. Figure 1 shows a schematic of a F28 fuselage with the removed section highlighted. Note the schematic shows the F28 MK1000 variant, which is slightly smaller than the MK4000. The major difference for current purpose is the diagram consists of only a single emergency exit, whereas the test article (the MK4000 variant) contains two emergency exits. However, the location on the test article is identical.

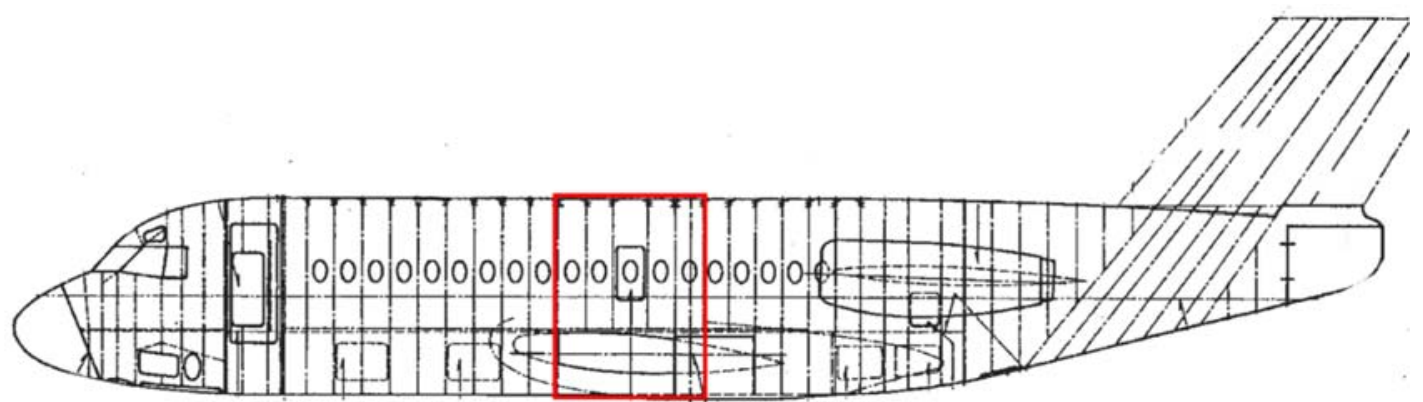

Figure 1 - Fokker F28 station diagram with Wingbox Section highlighted

The interior electronics, lighting, paneling and overhead bins were removed such that only the outer skin, frame and other structural components of the airframe remained. The floors and seats were removed for storage, and while the original floors were reinstalled and reused for test, the original seats were discarded. The wings were removed at the wingbox attachment points, and all fluids were drained from the remaining hydraulic lines that were still present in the wing truss structure and lower cavity below the wing truss structure. Two views of the test article are shown in Figure 2. The test article is in its original, un-instrumented condition. 

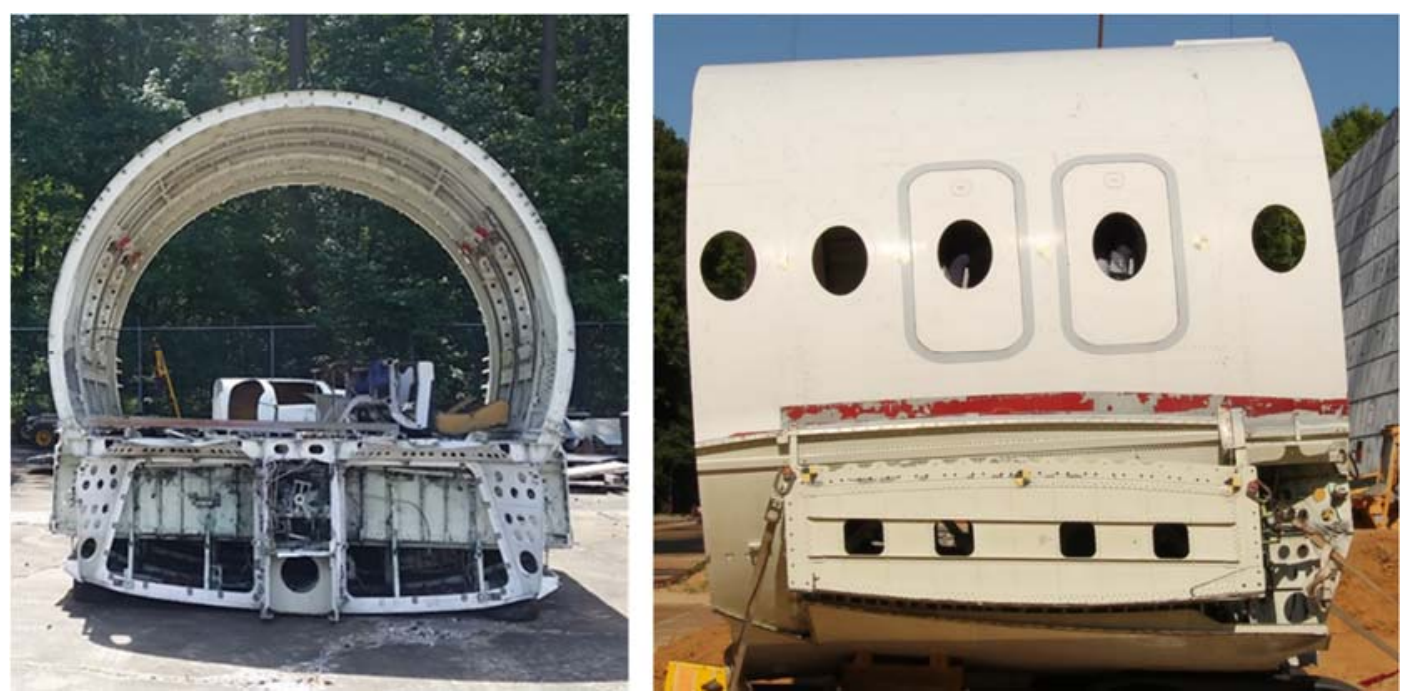

Figure 2 - Un-Instrumented F28 Wingbox Section aft view (left), and port side view (right)

Two rows of seats were installed in a triple-double configuration, with the triple seats installed on the starboard side of the section and the double seats installed on the port side. Seats were Code of Federal Regulations (CFR) Part 25.562 certified and were removed from an in-service Boeing 737 aircraft. Seat legs were reconfigured to interface with the seat track dimensions for the F28. For the double seats, the window seat was cut out of the triple configuration to achieve a double configuration. Seat track accelerations were measured by attaching an accelerometer at the base of the seat leg. The rear row of seats were placed between FS 10790 and 11405 while the front row of seats where centered over FS 10305. The seat pitch was $81.28 \mathrm{~cm}$ (32 in) between rows. All seats were placed in their most upright position and all armrests were placed up as to not interfere with the ATD motion. A combination of ATD sizes, ranging between $5^{\text {th }}$ and $95^{\text {th }}$ percentiles, were installed in the 10 seats onboard the test article. ATD results will be discussed in a future publication.

Overhead bins were simulated by adding lead ballast to aluminum c-channel sections, giving a total weight of approximately $11.34 \mathrm{~kg}$ (25 lb) per linear foot for a total of approximately $52.62 \mathrm{~kg}$ (116 lb) on each side. Aluminum c-channels were attached to the existing overhead bin location attachment points on the frames and spanned between FS 10305 and FS 11905. Accelerations were measured at the bin-frame attachment points on FS 10305 and FS 11405, and on the most forward and most aft lead ballast on each side. Figure 3 shows a close up of the overhead bins. 


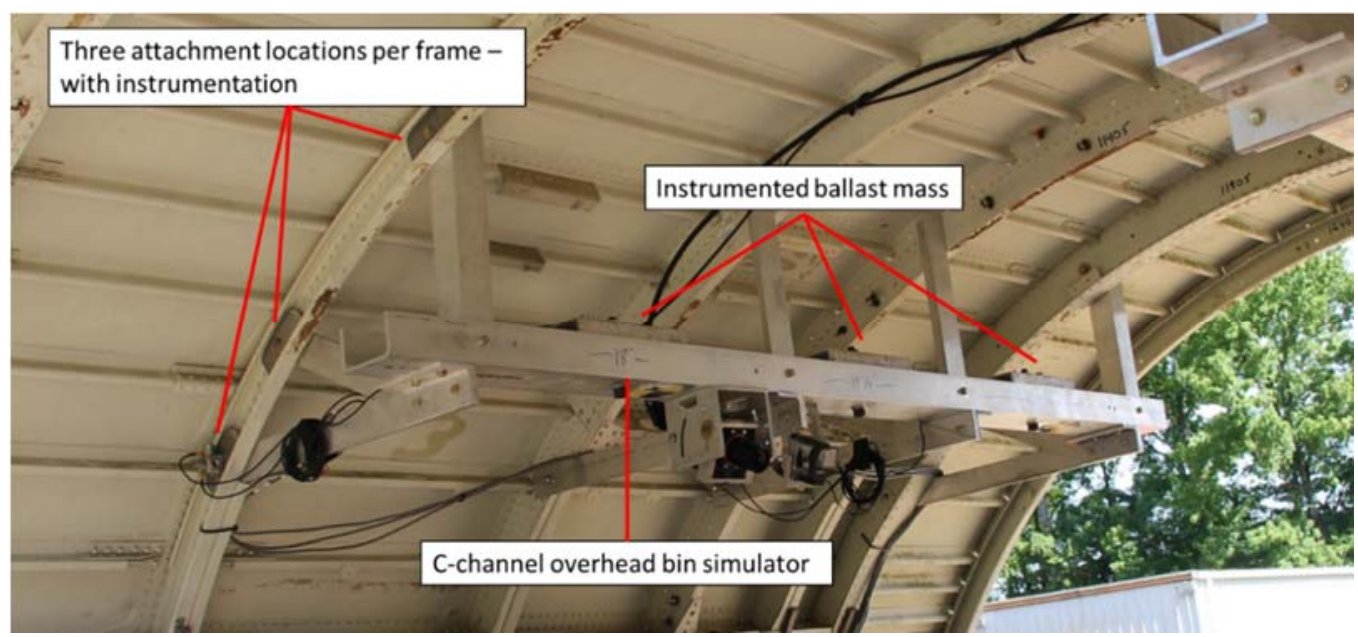

Figure 3 - Overhead bin simulators with ballast

Instrumentation included a suite of accelerometers to measure accelerations in the horizontal (x) and vertical (z) directions at critical points on the airframe. Accelerometers were located on the floor/frame section junctions, seat tracks, overhead lead ballast, overhead ballast/frame attachment points, and under the wingbox truss structure, near the cavity at the bottom of the test article. There were also two rotational rate sensors, one in the front and one in the aft, to measure the pitch rotation of the test article. All measurements were collected via a ruggedized onboard data acquisition system (DAS) sampling at $10 \mathrm{kHz}$. Additionally two standalone $500 \mathrm{~g}$ acceleration data loggers were added at two positions in the aft of the test article. The first was placed on a plate mounted on the inner seat track near the aft starboard side of the test article, and the second was placed on an unsupported span in the lower aft starboard cavity, near the bottom skin. These data recorders were set to initiate data logging via sensing a g-threshold limit, set at $20 \mathrm{~g}$, and would record three axis accelerations at 10 $\mathrm{kHz}$ for 10 seconds once initiated. An additional 6000-g shock recorder was also placed on the seat track at the aft starboard inner location, however this recorder did not trigger, so measurements were not collected. Figure 4 shows the instrumentation, seat and data system location for the test. 


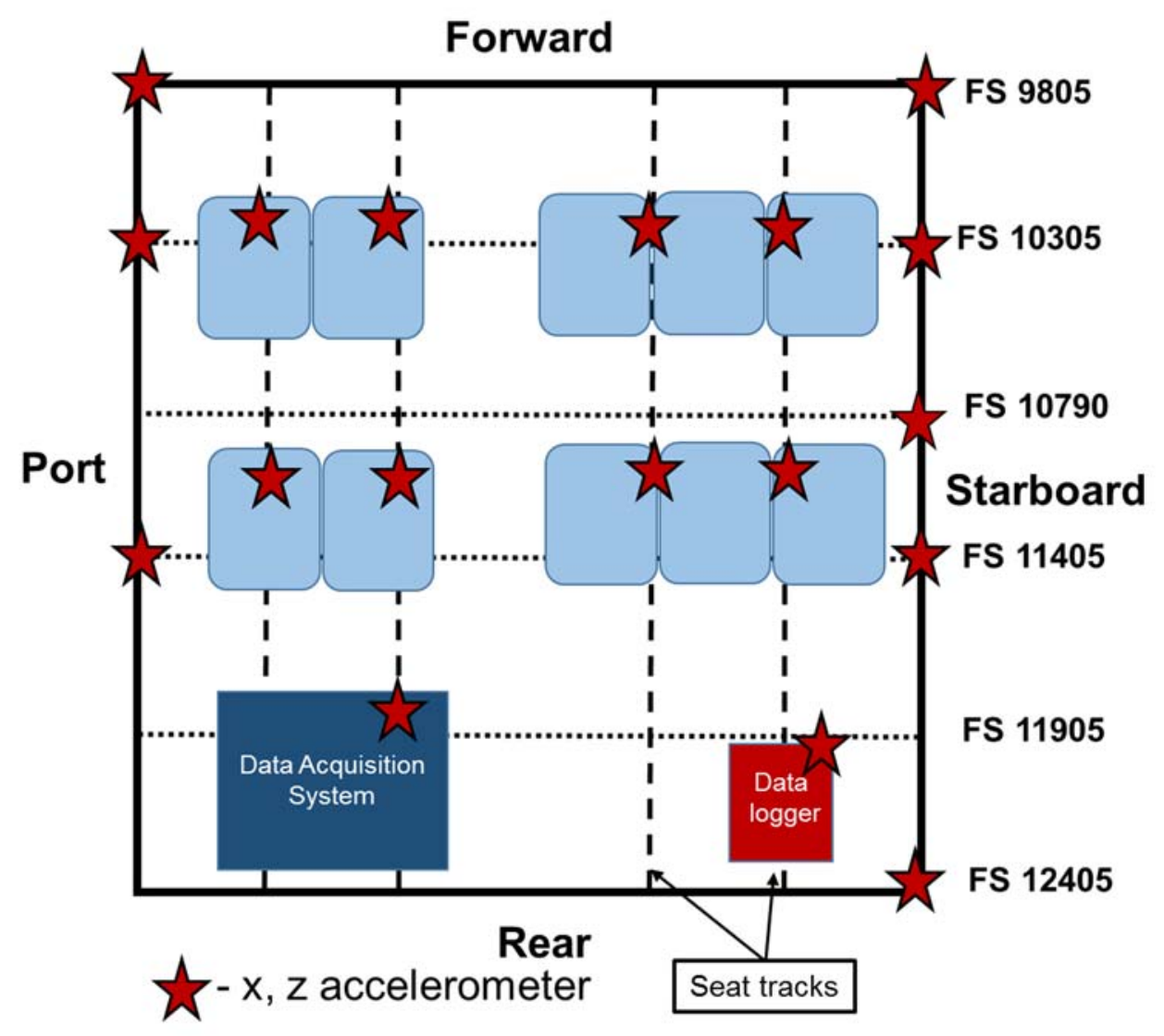

Figure 4 - Test article diagram showing seat configuration and floor level accelerometer locations

There were eight onboard cameras present for the test. There were two monochromatic high speed cameras imaging at 500 frames per second focused the double seat side and the triple seat side, respectively. The remainder were 1080p high definition (HD) cameras imaging at 60 frames per second. Onboard HD camera locations included an overhead view, a view of only the triple seats, a view of only the double seats, a view of the triple seat legs, a view of the internal wingbox truss structure, and a view of the cavity below the wingbox truss structure and the bottom skin.

There were eight external high speed cameras imaging the drop from all four sides at 1000 frames per second. These cameras were focused on the onboard occupants, test article release and free fall, and general test article motion during the test. A monochrome stochastic pattern was applied to the starboard side of the test article, in which $2.54 \mathrm{~cm}$ (1 in) black dots were hand painted over the white fuselage color. Each dot was to be used for full field digital image correlation (Littell 2016) for use in determining test article deformation during the impact event. Additional HD cameras were placed around the perimeter of the test area.

The total weight of the test article was 2,349.6 kg (5,180 lb). The center of gravity (CG) was $10.80 \mathrm{~cm}$ (4.25 in) forward of FS 10790 in the longitudinal direction and 
$3.56 \mathrm{~cm}$ (1.4 in) starboard of the geometric center in the lateral direction. The CG vertical height was not measured. The test article was lifted to its release height using soft straps and swivel hoist rings that were attached to the original wing attachment locations. The test article was pitched downward by utilizing lower wing attachment holes for the rear lifting locations than in the front. The nominal pitch measured at the floor level was calculated to be approximately 4.6 degrees, however it did not achieve a full 4.6 degree pitch during the drop. The impact conditions will be discussed further in the Experimental Results section.

The test article was impacted onto soil. The soil used at LandIR is known as Gantry Unwashed Sand (Thomas 2008) and was built into a $6.1 \mathrm{~m} \mathrm{(20} \mathrm{ft)} \mathrm{by} 6.1 \mathrm{~m} \mathrm{(20} \mathrm{ft)}$ square mound, with a downward facing 10 degree slope, such that the aft portion of the test article would contact first, causing a rotation component about the rear impact point. This rotation would cause the forward portion of the test article to impact at a downward pitch angle. The rotation was designed to induce a forward velocity into the onboard ATDs. The strength and stiffness properties of the soil were measured on test day, approximately 1 hour before the test occurred.

\section{EXPERIMENTAL RESULTS}

An image series showing significant events which occurred during the test is depicted from the south high speed camera view in Figure 5.

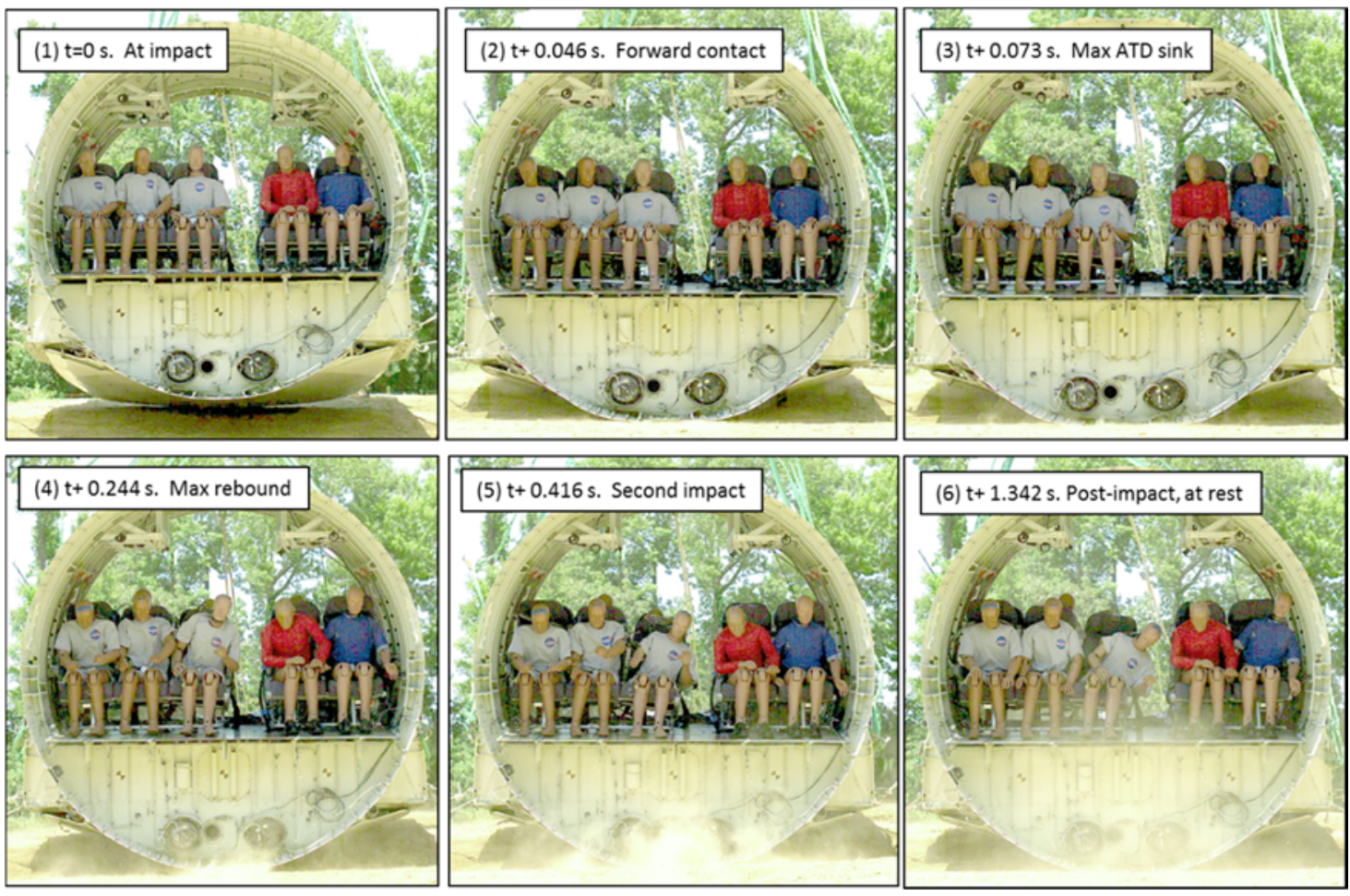

Figure 5 - Sequence of test events 
The initial contact of the aft portion of the test article onto the sloped soil surface was considered to be the initial impact, and is depicted in the top left image of Figure 5. It can also be noted that at initial impact, the forward portion of the test article is still in the air. Between impact and $t+0.046 \mathrm{~s}$, the test article rotated about the rear impact point, terminating with the forward portion of the test article initiating ground contact at $\mathrm{t}+0.046 \mathrm{~s}$, which is depicted in the top middle image. No sliding between impact at $\mathrm{t}+0.046 \mathrm{~s}$ was evident from the videos, so the horizontal acceleration between these two times was presumed to be from the test article rotation only. The next notable time occurred when the onboard ATDs experienced their maximum downward vertical motion, also known as their maximum sink position, which occurred at t $+0.073 \mathrm{~s}$, only slightly lagging the forward contact time. The test article and ATD appeared to exhibit uniform motion between $t+0.073 \mathrm{~s}$ and $\mathrm{t}+0.244 \mathrm{~s}$, which was the time when both test article and ATD rebounded to their maximum unloaded positions. There was a second impact of the test article that occurred at $\mathrm{t}+0.416 \mathrm{~s}$. During the second impact, the test article uniformly contacted the soil surface without rotational motion present. The test article came to rest shortly thereafter. A final position of the test article depicted in the lower right portion of Figure 5 shows the test article at rest, at a time well beyond where the final motion occurred during the test.

Other than the aft lower cavity, the test article did not show noticeable signs of structural damage. Additionally, all four emergency exit doors opened nominally posttest, indicating no signs of deformation or warpage on the skin or frames at the midcabin height. Figure 6 shows a close-up view of the aft lower cavity, pre- and posttest, which experienced the vast majority of the deformation during the test.
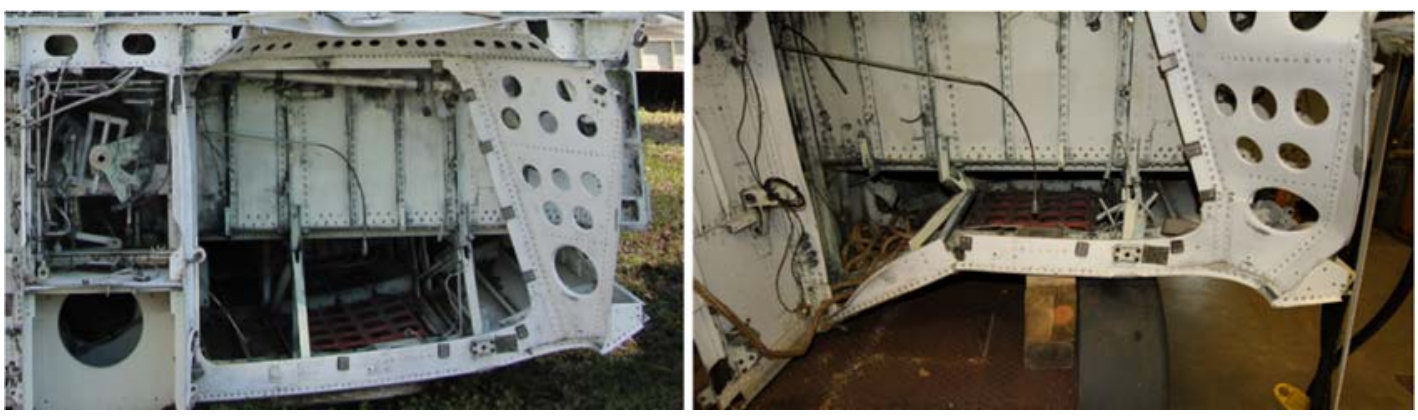

Figure 6 - Lower aft cavity. Before test (left) and damage post-test (right)

The velocity results were resolved from a series of four black and yellow bowtie targets placed on the port and starboard sides between the window openings at mid-cabin height. The target data showed the aft portion of the test article impacted the soil surface first at a pitch as determined from the floor of 2.9 degrees nose down with a vertical velocity of $8.99 \mathrm{~m} / \mathrm{s}(29.5 \mathrm{ft} / \mathrm{s})$ as viewed from a global coordinate system. The pitch down in combination with the sloped soil created induced local vertical and horizontal velocities. The four velocity traces were translated into the test article local coordinate system using calculations based on the pitch angle time history, and are shown in Figure 7, noting that positive horizontal velocity indicates motion of the test 
article forward, and positive vertical velocity indicates motion of the test article downward. The velocities were smoothed using a 5 point moving average, however no filtering was used. The individual velocity traces follow the same general trends, so the data were taken as a whole, with individual traces averaged together for reporting. The numbered vertical bars correspond to several image times shown in Figure 5.
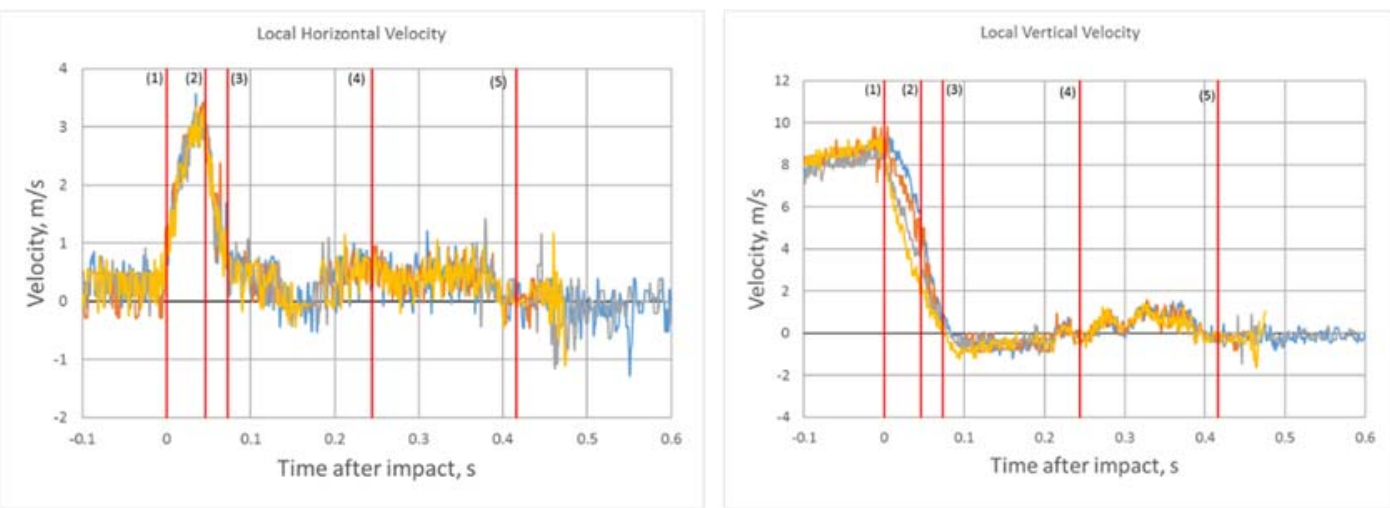

Figure 7 - Horizontal velocity results (left) and vertical velocity results (right) in the local coordinate system

The local vertical velocity was $8.87 \mathrm{~m} / \mathrm{s}(29.1 \mathrm{ft} / \mathrm{s})$ downward and the local horizontal velocity is $0.34 \mathrm{~m} / \mathrm{s}(1.1 \mathrm{ft} / \mathrm{s})$ forward at initial impact. The rotation of the test article after impact caused the local horizontal velocity to reach a peak of $2.92 \mathrm{~m} / \mathrm{s}(9.6 \mathrm{ft} / \mathrm{s})$ in the forward direction, which occurred before forward test article contact at $0.046 \mathrm{~s}$. Both the horizontal and vertical velocities approached zero at the maximum ATD sink at $0.073 \mathrm{~s}$, after which the vertical velocity averaged $0.49 \mathrm{~m} / \mathrm{s}(1.6 \mathrm{ft} / \mathrm{s})$ in the upward direction during the rebound ending with the test article at maximum rebound position at $0.244 \mathrm{~s}$ after impact. The second impact occurred with a forward velocity of 0.40 $\mathrm{m} / \mathrm{s}(1.3 \mathrm{ft} / \mathrm{s})$ and a vertical velocity of $0.46 \mathrm{~m} / \mathrm{s}(1.5 \mathrm{ft} / \mathrm{s})$, when examining averaged data between $0.244 \mathrm{~s}$ and $0.416 \mathrm{~s}$. After the second impact, the test article came to rest. Local horizontal accelerations measuring in the test article longitudinal direction are next plotted in Figure 8. These results, along with all acceleration data presented, were filtered in accordance to SAE J211 filtering schemes (Society of Automotive Engineering 1995). 


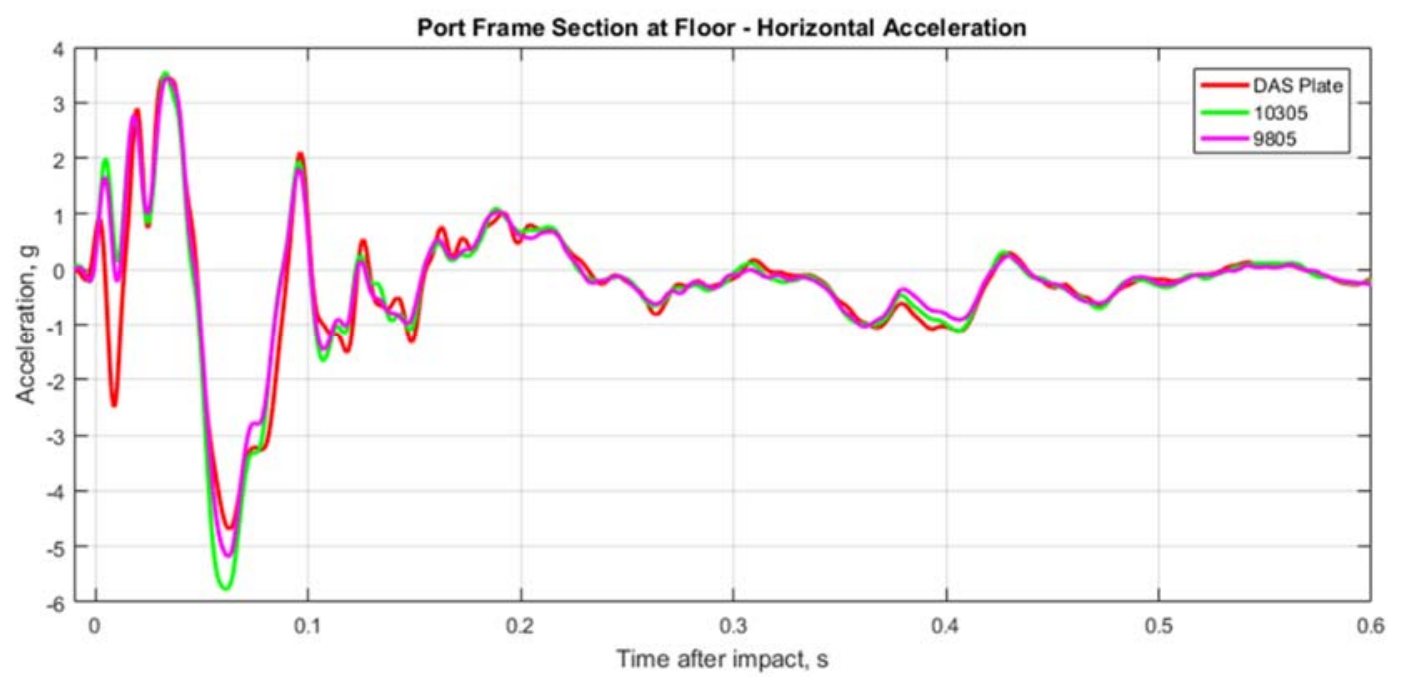

Figure 8 - Port floor level horizontal accelerations

The accelerometer at FS 11405 did not function during the test, so an accelerometer on the DAS plate, near FS 12405, was used in its place. Acceleration traces for all accelerometers closely matched throughout most of the impact event, with minor differences experienced in the negative peaks occurring at $0.64 \mathrm{~s}$. Positive acceleration peaks of $3.5 \mathrm{~g}$ occurred during the test article rotation up until initial forward impact at $0.046 \mathrm{~s}$, at which the acceleration responses fall back to crossing the zero g mark. The acceleration trace then went negative, reaching between $-4.7 \mathrm{~g}$ on the DAS plate to $5.7 \mathrm{~g}$ on FS 10305 until it crossed the zero g position again at $0.084 \mathrm{~s}$ after initial impact. The large negative accelerations were resultant from the fuselage inertia resisting further tip over due to the rotation at impact. As shown in the velocity data, a rebound occurred between $0.073 \mathrm{~s}$ and $0.244 \mathrm{~s}$ after impact, during which the accelerations headed in the positive direction toward a maximum of approximately $1 \mathrm{~g}$ at $0.192 \mathrm{~s}$ after impact, which was in the middle of the rebound motion. After $0.416 \mathrm{~s}$, the horizontal accelerations crossed the zero g position, which marked the beginning of the second impact. After the second impact, the accelerations oscillated about a zero g condition until motion stopped.

The soil moisture content was sampled at three locations to an average of $8.4 \%$ at the time of the test. The California Bearing Ratio (CBR) (American Society of Testing and Materials, 2016) was also measured and drop penetrometer readings were acquired in order to fully characterize the test day soil characteristics. The test article left an impression in the soil shown in Figure 9. 


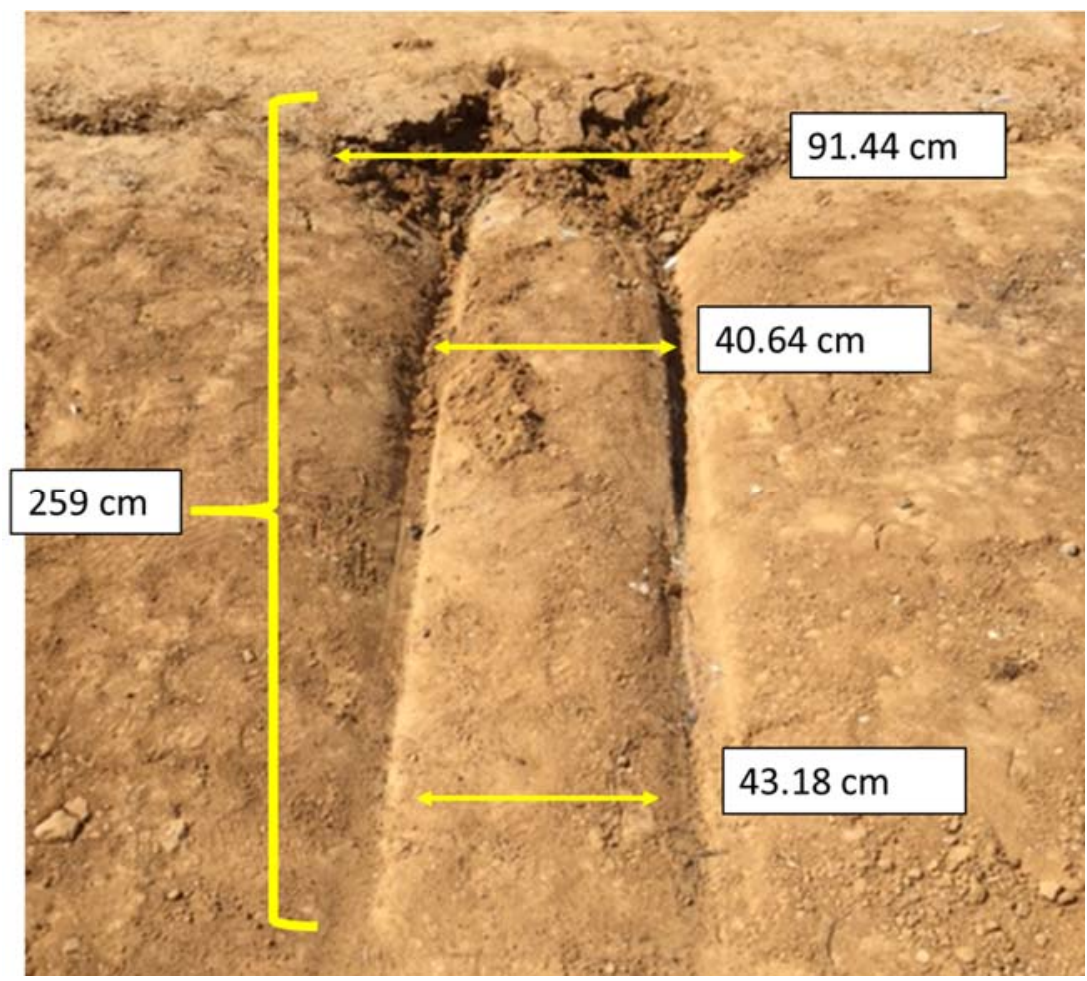

Figure 9 - Soil crater deformation with measurement overlay

The top of the image is toward the aft end of the test article. There are two distinct parallel vertical lines that show the deepest penetration near the aft of the test article and gradually become shallower when moving toward the front. The parallel lines were created by vertical stiffeners located at the bottom of the test article, approximately $22.9 \mathrm{~cm}$ (9 in) off the test article geometric centerline. Since the aft portion of the test article impacted first, the rear features, including the vertical stiffeners, made the deepest impression in the soil surface. Generally, the rest of the soil mound was undeformed due to the impact. The majority of the deformations appeared in the lower portion of the test article itself, which is shown previously in Figure 6. Table 1 presents the penetration measurements for three lateral locations at eight longitudinal positions in tabular form.

Table 1 - Soil crater depth measurements

\begin{tabular}{|c|c|c|c|}
\hline $\begin{array}{c}\text { Position from aft } \\
(\mathrm{cm})\end{array}$ & $\begin{array}{c}\text { Starboard track } \\
\text { depth }(\mathrm{cm})\end{array}$ & $\begin{array}{c}\text { Centerline depth } \\
(\mathrm{cm})\end{array}$ & $\begin{array}{c}\text { Port track depth } \\
(\mathrm{cm})\end{array}$ \\
\hline 38.1 & 17.8 & 10.8 & 18.4 \\
\hline 55.9 & 20.3 & 10.2 & 17.8 \\
\hline 94.0 & 20.3 & 10.2 & 20.3 \\
\hline 119.4 & 15.2 & 8.3 & 19.0 \\
\hline 157.5 & 15.2 & 6.4 & 15.2 \\
\hline 193.0 & 12.1 & 7.0 & 13.3 \\
\hline 259 & 7.6 & 7.6 & 7.6 \\
\hline
\end{tabular}


The soil crater measurement data marked differences between the vertical stiffener and bottom span locations. In the aft impact location, vertical stiffener penetration was $17.8 \mathrm{~cm}$ (7 in) into the soil on the starboard side and $18.4 \mathrm{~cm}$ (7.25 in) into the soil on the port side, while the location of the mid-span (not noted in Table 1 but visible in the side edges of the Figure 9) in the lower cavity of the test article penetrated very little into the soil. The difference are notable because accelerations obtained at these measured locations can provide a local loading profile. The acceleration data clearly showed difference in response between the aft subfloor accelerometer and the data logger on the cavity mid-span. Figure 10, left, shows the locations of both accelerometers in the post-test damaged view to contrast the differences in their locations. The data obtained are shown in Figure 10, right. The data logger was not time synchronized to the rest of the data so manual shifting was implemented on the data logger time data to give a more direct comparison. The data in Figure 10 are filtered using a Channel Frequency Class (CFC) 60 low-pass filter for visualization.
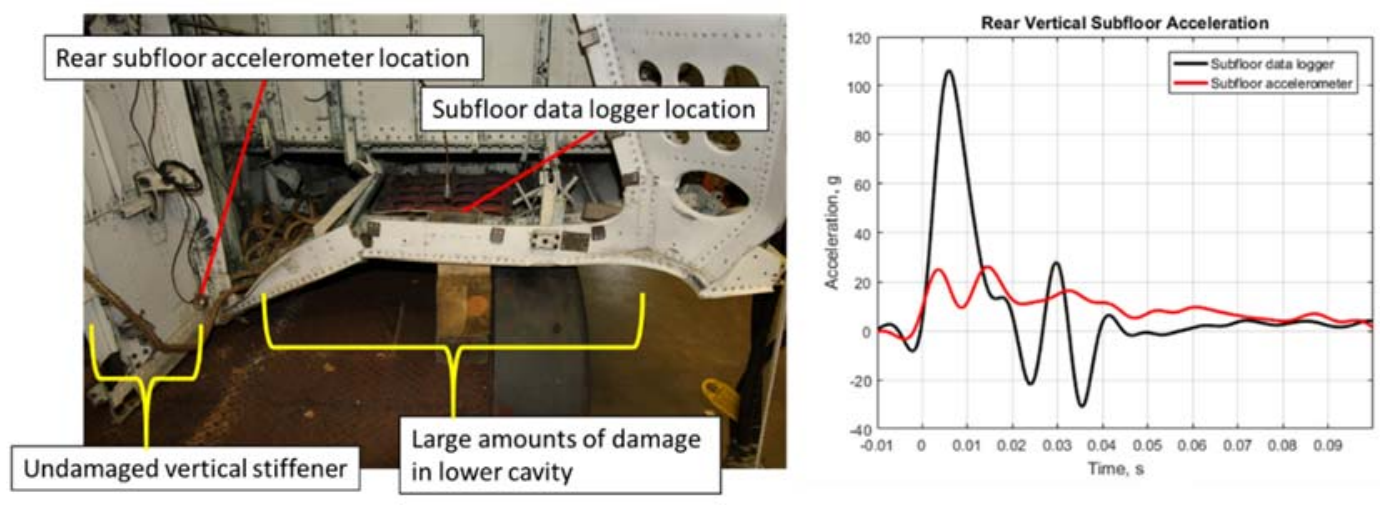

Figure 10 - Aft lower test article vertical deformations (left) and acceleration results (right)

The filtered data logger data showed a triangular pulse with a peak acceleration of approximately $106 \mathrm{~g}$ and duration of approximately $0.021 \mathrm{~s}$, if using the first data point for which the acceleration trace crossed the zero g mark after maximum. In contrast, the subfloor accelerometer located on the vertical stiffener produced accelerations that more closely matched the results from the airframe floor accelerometers, which will be described in detail later in this section. The vertical stiffener remained undamaged during the impact, but produced the deepest soil crater where penetration occurred, as shown in Figure 9, in a controlled manner throughout the initial rotation, front impact, and through ATD max sink. The soil penetration, along with the rotation limited the peak magnitude of $26.0 \mathrm{~g}$, having a total duration of $0.100 \mathrm{~s}$.

Figure 11 shows an image series of the aft lower cavity crushing to illustrate the differences in deformation at the two locations that the instruments were mounted. Note that the horizontal lines in the images are artifacts of the camera sensor not related 
to the test, test setup or results. These artifacts can be ignored when examining the images.
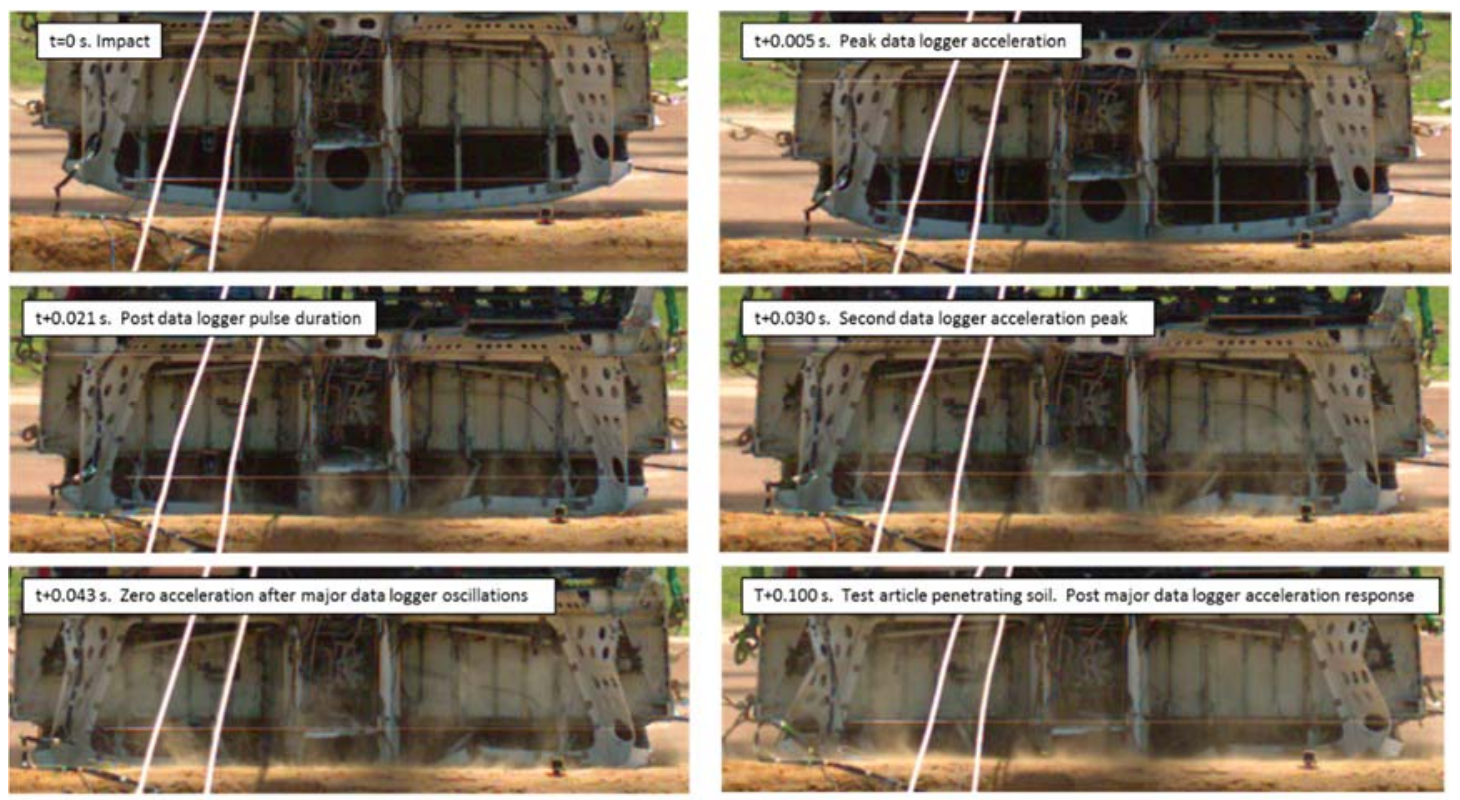

Figure 11 - Aft lower cavity deformation image series

The initial contact between the aft portion of the test article and the soil surface is shown in the upper left image in Figure 11. The peak data logger acceleration, shown in the upper right, of $106 \mathrm{~g}$ occurred $0.05 \mathrm{~s}$ later, which was before deformation initiation of the lower cavity supports occurred. The impact shape and magnitude of the acceleration response were a resultant between the bottom skin's large surface and soil contact in flat manner with no deformation. It is only after the $106 \mathrm{~g}$ peak that the lower cavity deformation initiated, and it was in the middle of deformation by the time the main data logger pulse finished at $0.021 \mathrm{~s}$, which is shown in the middle left image. After the $0.021 \mathrm{~s}$ mark, large amounts of lower cavity deformation occurred, which are captured in the middle right image taken at $0.030 \mathrm{~s}$ after impact, and the lower left image, taken at $0.043 \mathrm{~s}$ after impact. At the $0.100 \mathrm{~s}$ mark, the major acceleration pulses for both the data logger and the accelerometer on the vertical stiffener have concluded.

The results shown in Figure 11 along with post-test inspections of the test article determined the majority of the deformation occurred in the lower cavity below the floor and wingbox truss structure, near the bottom skin of the test article. The wingbox truss structure was significantly more stiff as compared to the other parts of the fuselage and did not exhibit any noticeable deformations. Furthermore, the structure above the floor and in the mid-cabin did not show any noticeable deformations, and, as previously stated, the emergency exit doors opened nominally, also suggesting any deformation which may have occurred at the floor level or above was purely elastic in nature. 
The starboard accelerations at the floor/frame junctions are shown in Figure 12. The data are filtered using a CFC 60 class filter and reported in the local aircraft coordinate system by measuring accelerations normal to the floor. In general, the pulse shape was trapezoidal in nature, having a total duration of approximately 0.100 to $0.120 \mathrm{~s}$ and an average plateau value of between $9.8 \mathrm{~g}$ and $12.2 \mathrm{~g}$ for times between 0.02 and $0.05 \mathrm{~s}$ after impact. The initial peak occurred at approximately $0.008 \mathrm{~s}$ after initial test article/soil contact. The peak values were greatest at the aft of the test article and decayed as the location moved toward the front. The highest peak of approximately $39.0 \mathrm{~g}$ occurred at FS 12405, which was followed by a peak of $26.3 \mathrm{~g}$ at FS 11405. The accelerations decayed until the forward-most section, FS 9805, was reached, in which there was no discernable peak exhibited $0.008 \mathrm{~s}$ after impact.

The second peak occurred approximately $0.055 \mathrm{~s}$ after impact, which was shortly after the time the forward portion of the test article made contact with the soil surface due to the rotation of the test article at impact. In contrast to the trend observed in the initial peaks in the response, the greatest magnitude in the second peak occurred in locations at the front of the test article. Specifically, the highest magnitude peak occurred at FS 9805 which exhibited an acceleration magnitude of approximately $31.7 \mathrm{~g}$, and decreased rearward, until a peak of approximately $12.1 \mathrm{~g}$ was observed at FS 12405.

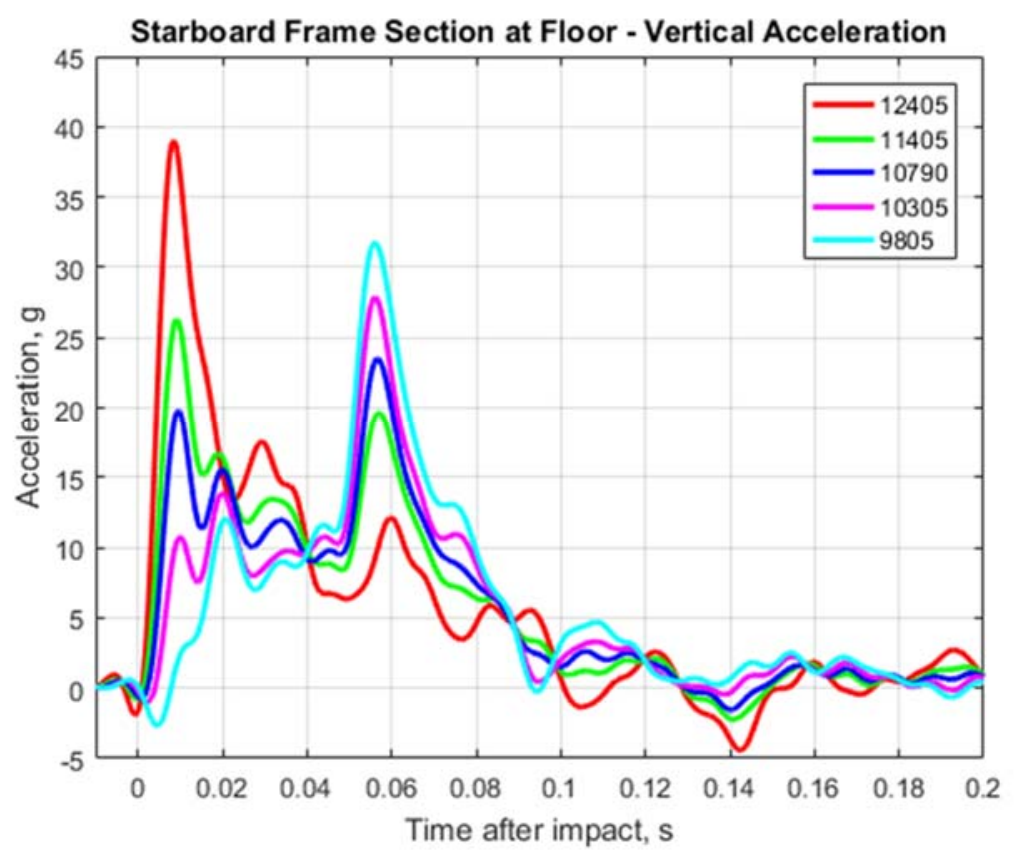

Figure 12 - Starboard frame section vertical acceleration

The bin results displayed the same trends as seen in the floor level accelerations, and are shown in Figure 13. The aft-most attachment point at FS 11405 experienced an initial peak of $28.5 \mathrm{~g}$ on the port side and $27.4 \mathrm{~g}$ on the starboard side and then settled into an average acceleration plateaus of $12.1 \mathrm{~g}$ and $11.5 \mathrm{~g}$ on the port and starboard 
side, respectively, when the data were averaged between 0.020 and $0.060 \mathrm{~s}$ after impact. In contrast, the forward-most bin/frame attachment locations at FS 10305 exhibited a peak near the end of the plateau region of the response, with peak values of $30.3 \mathrm{~g}$ and $35.9 \mathrm{~g}$ for the port and starboard, respectively. However, averaged data over the same $0.020 \mathrm{~s}$ and $0.060 \mathrm{~s}$ plateau region gave responses of $12.6 \mathrm{~g}$ and $13.3 \mathrm{~g}$ for the port and starboard sides, respectively.
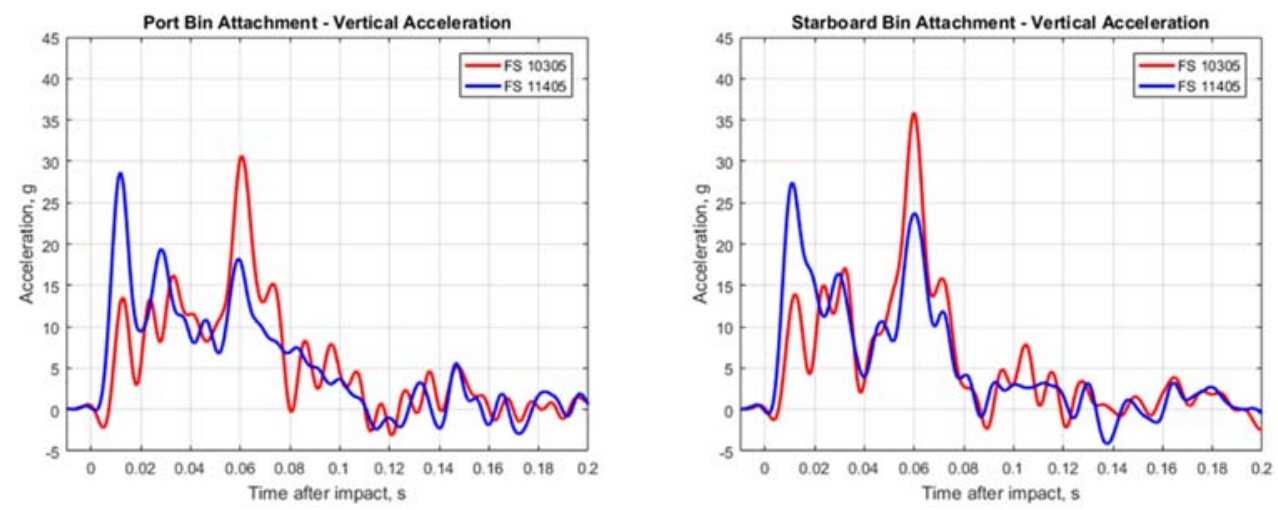

Figure 13 - Overhead bin attachment location vertical accelerations. Port side (left) and starboard side (right)

Accelerations recorded on the overhead bin ballast mass were of higher magnitude than either the bin attachment or floor accelerations. They also did not exhibit a trapezoidal pulse shape, but rather, showed an oscillatory response of between 26.6 and $27.2 \mathrm{~Hz}$ for all locations centered about zero g. The oscillations were a result the bin ballast masses and c-channels cantilevered off of the end of the attachment bars. The accelerations did however follow the general trend that the aft-most locations exhibited an initial peak during the initial contact, while the forward-most locations exhibited this peak after the front contact. The magnitudes for the peaks were $45.9 \mathrm{~g}$ and $46.8 \mathrm{~g}$ for the port and starboard FS 11405 locations, respectively, and $47.3 \mathrm{~g}$ and $53.5 \mathrm{~g}$ for the port and starboard FS 10305 locations, respectively, and are shown in Figure 14.
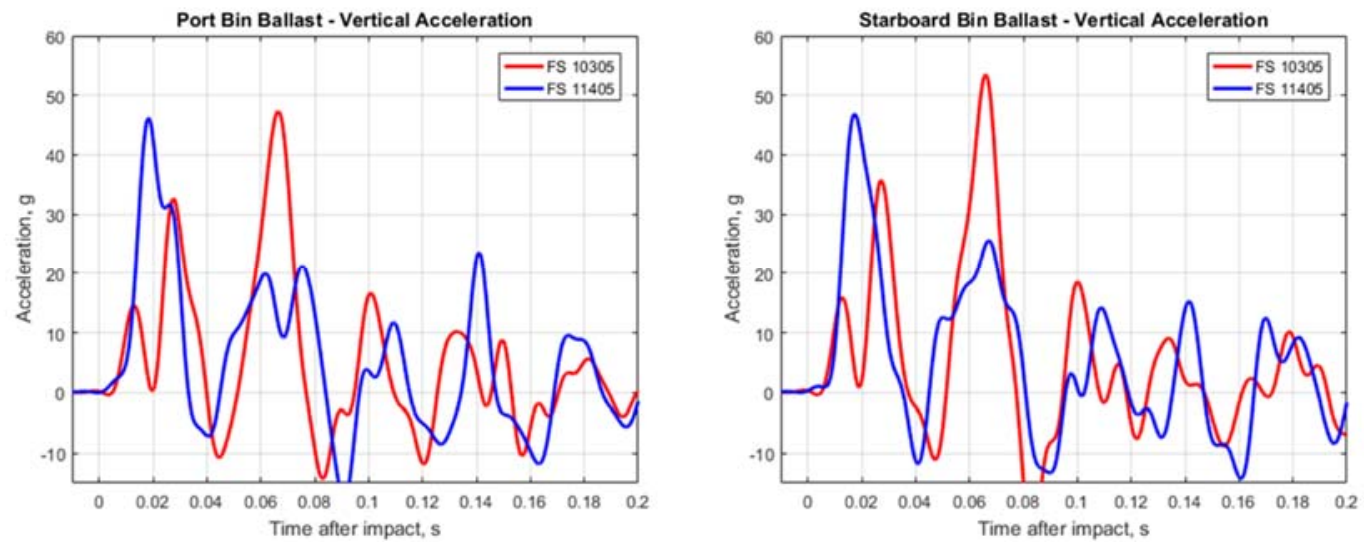

Figure 14 - Overhead bin ballast vertical accelerations. Port side (left) and starboard side (right) 
Additional items of interest from the test were the ATD responses and corresponding injury evaluations. While the ATD response and results will be presented in a separate publication, it was expected that the ATDs would experience differences in acceleration levels corresponding to differences in internal ATD forces depending on where the particular ATD was seated. The differences in the accelerations at the floor level at the various locations support this theory.

\section{CONCLUSION}

The wingbox fuselage drop test was successfully conducted on June $29^{\text {th }}$, 2017. The fuselage test article was outfitted with instrumentation, seats, ATDs, and cameras to capture the response before, throughout, and after the impact event. Unlike a pure vertical drop test onto a flat surface, an angle difference between the test article pitch angle and impact surface slope angle was present to induce a local horizontal acceleration during the test. The results showed that the difference in angle allowed for a maximum velocity of $2.92 \mathrm{~m} / \mathrm{s}(9.6 \mathrm{ft} / \mathrm{s})$ in the local horizontal direction to occur shortly after impact. The accelerations showed differences in responses when comparing results obtained from the aft of the test article to the result obtained from the front. A noticeable spike occurred in the vertical acceleration (either at the beginning or at the end of the pulse, depending on which sensor location was examined) but overall pulse shape was trapezoidal in nature with average levels of between $9.8 \mathrm{~g}$ and $12.1 \mathrm{~g}$ when examining acceleration on the starboard side of the test article. Inspections post-test showed the majority of the damage occurred in the lower cavity where crushing occurred due to the initial impact and rotation. The majority of the test article above the lower cavity location appeared to be undamaged.

Additionally, the conducted test presents a method to induce horizontal motion into a test article utilizing a purely vertical drop condition, sloped impact surface and a downward facing pitch angle. While not as fully comprehensive as full-scale swing testing which incorporates actual horizontal velocity component at impact, drop testing using angled surfaces could be sufficient for the evaluation of airframe crashworthiness and occupant response in future tests.

\section{REFERENCES}

Abramowitz, A., Ingraham, P.A., and McGuire, R.J. (1999) "Vertical Drop Test of a Shorts 3-30 Airplane.” DOT/FAA/AR-99/87.

Abramowitz, A., Smith, T.G., and Vu, T. (2000) "Vertical Drop Test of a NarrowBody Transport Fuselage Section with a Conformable Auxiliary Fuel Tank Onboard.” DOT/FAA/AR-00/56.

Abramowitz, A., Smith, T.G., Vu, T., and Zvanya, J. (2006) "Vertical Drop Test of an ATR 42-300 Airplane.” DOT/FAA/AR-05/56. 
American Society of Testing and Materials. "Standard Test Method for California Bearing Ratio (CBR) of Laboratory-Compacted Soils.” ASTM D1883. ASTM International, West Conshohocken, PA, 2016.

Fasanella, E.L., and Alfaro-Bou, E. (1986) "Vertical Drop Test of a Transport Fuselage Section Located Aft of the Wing.” NASA-TM-89025.

Federal Register. (2015) Federal Aviation Administration, Aviation Rulemaking Advisory Committee, Transport Airplane and Engine Issues, Vol 80.

Littell, J. D. (2016) "Experimental Photogrammetric Techniques used on Five FullScale Aircraft Crash Tests.” NASA TM-2016-219168.

Logue, T.V., McGuire, R.J., Reinhardt, J.W., and Vu, T. (1995) "Vertical Drop Test of a Narrow-Body Fuselage Section with Overhead Stowage Bins and Auxiliary Fuel Tank System On Board.” DOT/FAA/CT-94/116.

McGuire, R.J., Nissley, W.J., and Newcomb, J.E. (1993) "Vertical Drop Test of a Metro III Aircraft.” DOT/FAA/CT-93/1.

McGuire, R.J., and Vu, T. (1998) "Vertical Drop Test of a Beechcraft 1900C Airliner." DOT/FAA/AR-96/119.

Society of Automotive Engineering. (1995) J211-1 Instrumentation for Impact Test Part 1-Electronic Instrumentation, Revision March 1995. SAE International, 400 Commonwealth Drive, Warrendale, PA.

Thomas, M.A., Chitty, D.E., Gildea, M.L., T’Kint, C.M. (2008) “Constitute Soil Properties for Unwashed Sand and Kennedy Space Center.” NASA CR2008-215334.

Vaughan, V.L., and Alfaro-Bou, E. (1976) "Impact Dynamics Research Facility for Full-Scale Aircraft Crash Testing.” NASA-TN-8179.

Williams, M.S., and Hayduk, R.J. (1983) "Vertical Drop Test of a Transport Fuselage Center Section Including the Wheel Wells.” NASA-TM-85706. 